\title{
Additive Manufacturing Techniques for the Production of Tissue Engineering Constructs
}

\begin{tabular}{|r|l|}
\hline Journal: & Journal of Tissue Engineering and Regenerative Medicine \\
\hline Manuscript ID: & Draft \\
\hline Wiley - Manuscript type: & Review \\
\hline Date Submitted by the Author: & n/a \\
\hline Kemplete List of Authors: & $\begin{array}{l}\text { Mota, Carlos; University of Pisa, Laboratory of Bioactive Polymeric } \\
\text { Materials for Biomedical and Environmental Applications (BIOLab), UdR- } \\
\text { INSTM, Department of Chemistry and Industrial Chemistry } \\
\text { Puppi, Dario; University of Pisa, Laboratory of Bioactive Polymeric Materials } \\
\text { for Biomedical and Environmental Applications (BIOLab), UdR-INSTM, } \\
\text { Department of Chemistry and Industrial Chemistry } \\
\text { Chiellini, Federica; University of Pisa, Laboratory of Bioactive Polymeric } \\
\text { Materials for Biomedical and Environmental Applications (BIOLab), UdR- } \\
\text { INSTM, Department of Chemistry and Industrial Chemistry } \\
\text { Chiellini, Emo; University of Pisa, Chemistry \& Industrial Chemistry }\end{array}$ \\
\hline Keywords: & $\begin{array}{l}\text { Additive manufacturing, Solid freeform fabrication, Tissue engineering, } \\
\text { Regenerative medicine, Tissue and organ printing, Scaffold }\end{array}$ \\
\hline
\end{tabular}




\title{
Additive Manufacturing Techniques for the Production of Tissue \\ Engineering Constructs
}

\author{
Carlos Mota ${ }^{1}$, Dario Puppi ${ }^{1}$, Federica Chiellini ${ }^{1}$, Emo Chiellini, ${ }^{1, *}$ \\ ${ }^{1}$ Laboratory of Bioactive Polymeric Materials for Biomedical and Environmental Applications (BIOLab), UdR- \\ INSTM, Department of Chemistry and Industrial Chemistry, University of Pisa, via Vecchia Livornese 1291, 56010 \\ San Piero a Grado (Pi), Italy. \\ * Correspondence to: Emo Chiellini, e-mail: emochie@dcci.unipi.it, Tel: +39 050 2210301, Fax: +39 0502210332
}

\section{Table of Contents}

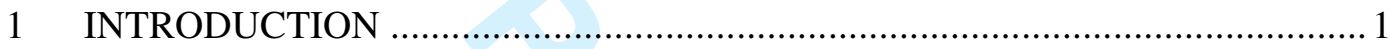

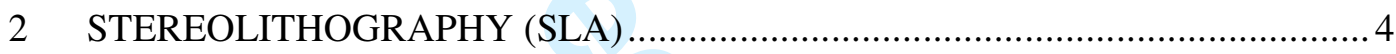

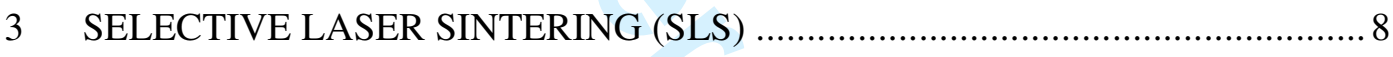

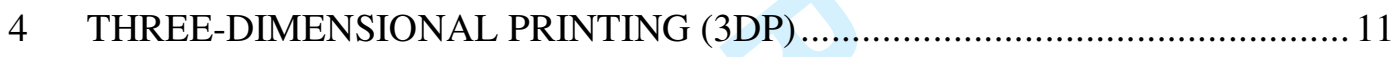

5 MELT-EXTRUSION BASED TECHNIQUES ……………….......................... 13

6 SOLUTION/SLURRY EXTRUSION BASED TECHNIQUES............................. 18

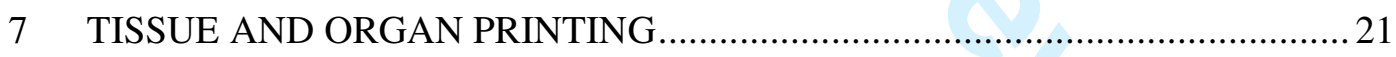

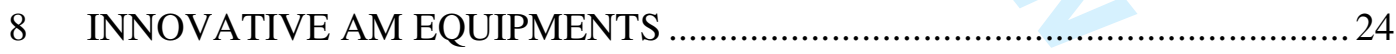

9 CONCLUSIVE REMARKS AND FUTURE PERSPECTIVES ………...............26

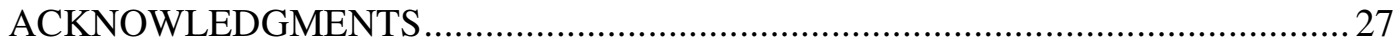

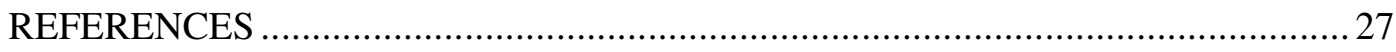

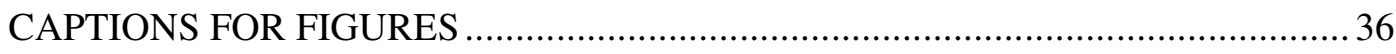

Keywords: additive manufacturing, solid freeform fabrication, tissue engineering, regenerative medicine, scaffold 


\begin{abstract}
Additive Manufacturing (AM) refers to a class of manufacturing processes based on the building of a solid object from three-dimensional (3D) model data by joining materials usually layer upon layer. Among the vast array of techniques developed for the production of Tissue Engineering (TE) scaffolds, AM techniques are gaining great interest for their suitability in achieving complex shapes and microstructures with high degree of automation, good accuracy and reproducibility. In addition, the possibility of fast producing tissue engineered constructs meeting patient's specific requirements, in terms of tissue defect size and geometry as well as autologous biological features, makes them a powerful way for enhancing clinical routine procedures. This paper gives an extensive overview of different AM techniques classes (i.e. stereolithography, selective laser sintering, three-dimensional printing, melt-extrusion based techniques, solution/slurry extrusion based techniques, and tissue and organ printing) employed for the development of tissue engineered constructs, by highlighting their principles and technological solutions.
\end{abstract}

\title{
1 Introduction
}

The emergence in the last two decades of novel regenerative approaches in the biomedical field has raised the need for new technologies employable in the processing of biodegradable polymeric materials with tailored physico-chemical structural features and degradation properties. This has led to the development of a range of novel techniques and methodologies enabling the fabrication of micro- and nano-structured biodegradable constructs suitable for applications in Tissue Engineering (TE) and 
Regenerative Medicine.

TE typically involves the use of what is commonly referred to as scaffold that serves as temporary template for cells interactive trafficking and for the formation of the extracellular matrix (ECM), thus providing structural support for the newly formed tissue (Mano et al., 2007). A successful scaffold should meet some basic requirements, generally involving biocompatibility, biodegradability with controlled kinetics, interconnected porous structure with a tailored pore size, mechanical properties close to the target tissue and predefined geometry and size.

A broad variety of biomaterials have been tested for TE scaffolds, ranging from natural polymers showing biological cues suited to promote desirable cell responses, to synthetic polymers with more controllable physico-chemical, mechanical and processing properties (Place et al., 2009, Puppi et al., 2010a). Recent evidence suggests that, besides material chemistry, scaffold micro- and nano- structural features affect cell adhesion, spreading, growth, propagation and reorganization (Leong et al., 2003, Karageorgiou and Kaplan, 2005, Stevens and George, 2005, Puppi et al., 2010b, Mota et al., 2011). Depending on scaffolding material and TE strategy, different processing techniques and methodologies have been proposed to optimize final scaffold performances in terms of external shape and size, surface morphology and internal architecture. These include, among others, solvent casting combined with particulate leaching, freeze drying, gas foaming, melt moulding, fiber bonding, phase separation techniques, electrospinning and additive manufacturing (AM) techniques (also known as solid freeform fabrication techniques) (Puppi et al., 2010a).

$\mathrm{AM}$ is defined as "the process of joining materials to make objects from threedimensional (3D) model data, usually layer upon layer" (ASTM, 2012) and it has been 
extensively applied for the fabrication of TE scaffolds by means of different techniques, such as stereolithography (SLA) and fused deposition modeling (FDM) (Woodruff and Hutmacher, 2010). These techniques enable to obtain 3D structures with a predefined geometry and size, and with a porous architecture characterized by a fully interconnected network of pores with customizable size, shape and distribution. 3D model data for scaffold development can derive from medical imaging techniques used for diagnostic purposes, such as computer tomography (CT) and magnetic resonance imaging (MRI), and are generally treated by computer-aided design (CAD) and computer-aided manufacturing (CAM) software (Sun and Lal, 2002, Hieu et al., 2005) (Figure 1). Alternatively a simplified 3D model can be directly designed in CAD software or developed by means of mathematical equations (Gabbrielli et al., 2008) or topological optimization (Almeida and Bártolo, 2010). Most of CAD software converts the 3D model into a STL (Standard Tessellation Language) file containing the information of the 3D object surface geometry. The STL file is then sliced into layers originating a slice file (SLI) that is loaded digitally into the machine that drives the motions of the build parts.

Depending on the fabrication principle, the most extensively applied AM techniques for TE scaffolds fabrication have been conventionally classified into four categories: i) Stereolithography (SLA), ii) Selective Laser Sintering (SLS), iii) Three-Dimensional Printing (3DP) and iv) Fused Deposition Modeling (FDM) (Hutmacher et al., 2004). However, a number of AM techniques based on either well-known industrial technologies or on innovative principles are being introduced in the TE field and adapted to meet the requirement of materials processing for scaffold fabrication. The wide range of innovative AM techniques recently developed has often led to debatable 
terminology for the definition of techniques combining principles inherent to different classes of the aforementioned classification (Figure 2).

This review is dealing specifically with AM techniques, currently investigated for the development of scaffolds or living constructs for TE applications, by highlighting their basic principles and open issues.

\section{Stereolithography (SLA)}

SLA is an AM technique that uses an ultraviolet (UV) light or laser to selectively polymerize layers of a photosensitive polymer (Figure 3a). The first studies on the production of 3D objects by selective photopolymerization of a liquid resin using UV light were performed at the beginning of eighties by Kodama (Kodama, 1981), who developed two approaches: one using masks for the definition of each layer structure; the other one involving the use of an optical fiber to selectively polymerize the liquid resin. In the latter case, a predefined pattern was achieved by controlling the movement of the fiber in the $\mathrm{X}$ and $\mathrm{Y}$ axis. In 1986, Hull attributed the denomination of SLA to the process of producing 3D solid objects layer-by-layer by means of UV light (Hull, 1986, Hull, 1990).

After the polymerization of a layer, the construction platform lowers of a given distance and a recoat bar places a new uniform layer of resin on top of the previously built one. In order to prevent delamination between adjacent layers, the polymerization of a layer is carried out by overlapping a percentage of the previous built layer. The layer-by-layer process is repeated until the $3 \mathrm{D}$ object is finally built up. Further processing steps include the removal of the non-polymerized resin and the post-curing of the green part in order to improve polymerization between layers and to reduce surface irregularities (Hutmacher et al., 2004, Melchels et al., 2010b). 
A recently developed SLA technique involves a digital light projector source to direct light using a Digital Micromirror Device ${ }^{\mathrm{TM}}\left(\mathrm{DMT}^{\mathrm{TM}}\right)$ constituted by an array of mirrors that selectively divert the light to the vat containing the photopolymerizable polymer (Melchels et al., 2010b). This technique involves the use of smaller quantity of photopolymer when compared to conventional SLA equipments.

The preparation of photocrosslinkable liquid resins generally requires toxic solvents (Elomaa et al., 2011), and the commercially available resins (epoxy-based or acrylatebased) suitable for SLA processing present lack of biocompatibility and biodegradability (Jansen et al., 2008, Melchels et al., 2010b). For such reasons, the first attempts to use SLA technology for the production of biomedical implants were made carrying out an indirect approach. Levy et al employed a slurry made from a suspension of hydroxyapatite (HA) powder into a liquid photocurable acrylic resin (Levy et al., 1999). After the laser curing process, the acrylic resin was removed by heating in order to obtain a porous HA prosthesis. A "lost-mould" approach was developed by Chu et al who infiltrated an epoxy mould with a HA suspension in acrylate binders; afterwards the mould and the binders were removed by pyrolysis, followed by a sintering process (Chu et al., 2001). The direct use of SLA technology to produce scaffolds was only possible after the development of new biocompatible and biodegradable materials. However, the amount of photopolymerizable biomaterials processed using SLA with properties suitable for TE applications is still limited (Hutmacher et al., 2004). Recently, new photocurable polymers with enhanced properties for scaffolds production have been developed. Polymer networks with tunable hydrophilicity and mechanical properties, prepared by photocrosslinking fumaric acid monoethyl ester functionalized with three-armed poly(D,L-lactide) (PDLLA) oligomers and using N-vinyl-2- 
pyrrolidone as diluent and comonomer, showed good cytocompatibility during in vitro cell culture experiments employing mouse preosteoblasts (Jansen et al., 2008). Using SLA, porous structures with well-defined gyroid architecture were prepared from these novel photocurable polymers. A recent study reported on the preparation of porous polylactide constructs by SLA without the use of reactive diluents (Melchels et al., 2009). Star-shaped (PDLLA) oligomers were functionalized using methacryloyl chloride and photocrosslinked in the presence of ethyl lactate as a non-reactive diluent enabling the production of porous scaffolds and films (Melchels et al., 2009). The films were seeded with murine preosteoblasts that adhered and proliferated well, although cell viability was significantly lower than the control grown on tissue culture polystyrene. The previously mentioned PDLLA based resin was used for the production of scaffolds with gyroid architecture that were characterized in comparison with a random pore architecture resulting from salt leaching (Melchels et al., 2010a). After dynamic seeding followed by 5 days of static culture, gyroid scaffolds showed large cell populations in the inner part of the scaffold, while salt-leached scaffolds were covered with a cell sheet on the outside and no cells were found in the scaffold centre.

UV crosslinked natural or synthetic hydrogels are often employed in combination with cells for the engineering of soft tissues because of their ability of triggering cell responses and inducing the formation of new tissue (Tsang and Bhatia, 2004, Fedorovich et al., 2007). Several factors, such as UV light intensity, exposure time, and free radicals that can be generated from the photoinitiator, determine the success of cells encapsulation (Lu et al., 2006). As an example, poly(ethylene oxide) and poly(ethylene glycol)dimethacrylate photopolymerizable hydrogels were used for the production of constructs encapsulating chinese hamster ovary cells by means of SLA, achieving good 
cell vitality by minimizing the amount of the photoinitiatior that could have toxic effects (Dhariwala et al., 2004). Further improvements carried out by Arcute et al (Arcaute et $a l ., 2006)$ on poly(ethylene glycol) dimethacrylate hydrogels allowed an increase in the survival of encapsulated human dermal fibroblasts observed after 24 hours.

Considerable drawbacks of SLA are represented by the shrinkage of the scaffold structure during the production process and the post-processing step, the necessity of auxiliary supports for the construction of complex geometries, the difficulty of loading bioactive agents and obtaining multi-material structures (although new approaches involving the combination of vats containing different resins have been recently proposed (Choi et al., 2011)) (Wang et al., 1996). In addition, SLA has a typical resolution in the range of $150 \mu \mathrm{m}$ in the three space directions. While the vertical resolution (along the built axis) is mainly related to the chemistry of the process, and therefore it can be enhanced by modifying the photosensitive resins, major improvements in the lateral resolution (in-plane) are related to the resolution of the scanning system used for resin surface irradiation and to the quality and stability of the light beam (Bertsch and Renaud, 2011). A number of microstereolitography ( $\mu$ SLA) techniques have evolved from SLA to improve the resolution of the manufacturing process. These include Constrained Surface and Free Surface $\mu$ SLA techniques that use a vector-by-vector tracing of each layer of the object, and Integral $\mu$ SLA techniques that are based on the projection of a high resolution image created by a dynamic mask on the surface of the photosensitive resin. For instance, poly(propylene fumarate), a biodegradable and UV photocurable material, was investigated for the production of scaffolds for bone TE by means of different $\mu$ SLA techniques (Choi et al., 2009, Lan et al., 2009, Lee et al., 2009). In addition sub-micron $\mu$ SLA processes involving the 
manufacturing of the object directly inside the reactive medium, without layers superimposing, have been recently developed. Among them, two-photon $\mu$ SLA allows to achieve size resolution down to $100 \mathrm{~nm}$ by employing a femtosecond laser (WeiÃ et al., 2009). The first study proposing two-photon $\mu$ SLA for the development of polymeric porous structures was carried out by Ovsianikov et al (Ovsianikov et al., 2007) who investigated two commercially available materials, ORMOCER ${ }^{\circledR}$ (hybrid organic-inorganic polymeric material) and SU8 (epoxy-based polymer). The developed $3 \mathrm{D}$ structures showed good in vitro cytocompatibility but their application for TE purposes was limited by the lack of biodegradability. New biodegradable materials suitable for processing by means of two-photon $\mu$ SLA have been recently developed. For instance, the biodegradable triblock copolymer poly(e-caprolactone-cotrimethylenecarbonate)- $b$-poly(ethylene glycol)- $b$-poly( $\varepsilon$-caprolactone-cotrimethylenecarbonate) combined with 4,4'-bis(diethylamino)benzophenone as photoinitiator was recently employed to produce scaffolds with a resolution of $4 \mu \mathrm{m}$, although the developed structure suffered from distortion most likely due to polymer shrinkage during polymerization (Claeyssens et al., 2009).

\section{Selective Laser Sintering (SLS)}

Selective laser sintering (SLS) was developed and patented by Deckard in 1989 (Deckard, 1989) and it is based on the selective sintering of a polymer, ceramic or hybrid powder bed using a high intensity laser beam (e.g. $\mathrm{CO}_{2}$ laser) (Figure 3b). After the generation of a layer by selective particles bonding, a new powder bed is spread mechanically by a roller on top of the previous one to build up the 3D object layer-bylayer. The sintering process is performed with proper laser intensity capable of bonding the particles in a layer and also between adjacent layers in order to form a cohesive 3D 
structure. The dissociated or not-sintered areas serve as support for the subsequent layers.

The mechanical properties and the size accuracy of the scaffolds prepared by SLS are strongly dependent on the construction plane and processing parameters, such as manufacturing direction, scan spacing, size of the particles and laser intensity (Ciardelli et al., 2005, Williams et al., 2005, Eosoly et al., 2010). Generally the scaffolds produced with this technique present low mechanical properties, thus limiting their application to not-load bearing sites (Eosoly et al., 2010, Duan et al., 2011b, Krishna et al., 2011). However, the studies using SLS technique generally aim at the production of scaffolds for bone TE, although recently the production of scaffolds for cardiac tissue regeneration was also investigated (Yeong et al., 2010).

Initial experiments on the production of TE scaffolds by SLS was performed in 2003 employing a blending of polyetheretherketone and HA (Tan et al., 2003). Subsequently, anatomically shaped poly( $\varepsilon$-caprolactone) (PCL) scaffolds were successfully fabricated by SLS, showing mechanical properties within the lower range of trabecular bone and the ability to support in vivo bone tissue growth (Williams et al., 2005). Further studies reported the development of PCL/HA composite scaffolds by SLS demonstrating how it is possible to control the scaffold morphology by changing the processing parameters (Wiria et al., 2007, Eosoly et al., 2010).

Poly(L-lactide) (PLLA)-based composite scaffolds were also produced by processing a bed of PLLA or PLLA/carbonated HA nanocomposite microspheres (Zhou et al., 2010). However, the developed scaffolds presented an irregular morphology, due to nonhomogenous fusion of nanocomposite microspheres, but they were able to support the in vitro adhesion of human osteoblast-like cells. 
A number of recent studies have reported on the development of poly(hydroxybutyrateco-hydroxyvalerate)/tricalcium phosphate (PHBV/TCP) scaffolds by applying SLS to composite microspheres (Duan and Wang, 2010a, Duan and Wang, 2010b, Duan et al., 2010, Duan et al., 2011a, Duan et al., 2011c). The bioactivity of the composite scaffolds was enhanced by loading the microspheres with bovine serum albumin as model protein (Duan and Wang, 2010b) or by physically entrapping gelatine on scaffold surface (Duan et al., 2011c) and binding human bone morphogenetic protein-2 (BMP-2) to heparin immobilized on gelatine-modified scaffold surface (Duan and Wang, 2010a).

Recent studies have proposed SLS for the manufacturing of bioactive ceramic scaffolds. For instance, bioactive glasses were processed in combination with stearic acid used as binder (Krishna et al., 2011). After removal of stearic acid, the scaffolds presented a pore size in the range of 300 to $800 \mu \mathrm{m}$, and an average porosity of 50\%. In vitro cell culture experiments with mouse osteoblasts showed an increase during six days of cell proliferation over the scaffold section. Recently, a binder-free approach involving the direct sintering of HA nanoparticles was shown to be suitable for the fabrication of simple structure scaffolds (Shuai et al., 2011).

Hybrid scaffolds combining synthetic and natural polymers by SLS are not commonly investigated due to the fast degradation of the natural components when submitted to laser beam treatment. However scaffolds composed of PCL and different polysaccharides (starch, gellan and dextran) showed only superficial degradation of the polysaccharides, while the bulk remained unchanged (Ciardelli et al., 2005). The incorporation of gellan and starch allowed enhancing cell adhesion on the produced constructs. 
Despite of the advantages of SLS (e.g. no need of construction support), the biomaterials in the form of fine powder suitable to be processed by this technique are limited and their cost is high (Zhou et al., 2010). Moreover, most of the methodologies for the preparation of polymeric and ceramic particles are still performed at lab scale for non-commercial purposes. Other concerns associated with this technique are the difficulty of eliminating the entrapped material inside complex geometries, and the poor control over surface topography that is generally defined by particles size and geometry (Ciardelli et al., 2005, Butscher et al., 2011).

\section{Three-Dimensional Printing (3DP)}

Three-dimensional printing (3DP), originally developed at Massachusetts Institute of Technology at the beginning of the 1990s (Sachs et al., 1990, Sachs et al., 1993), is based on the controlled deposition of a binder material laid on a powder layer by using an ink-jet head (Figure 3c). After the selective deposition of the binder, a new layer of powder is placed on top of the previous one and the process of deposition restarts. The unbound powder that composes each layer acts as support for the object being built. After the fabrication of each layer, the construction platform containing the powder layer moves downward a distance equivalent to the thickness of the layer deposited. The layer-by-layer process goes on until the $3 \mathrm{D}$ object is finally built. The high production rate and the possibility of obtaining large size models at a low cost make this process interesting for industrial applications.

Polymeric, ceramic and composite powder materials have been investigated for the production of TE scaffolds by 3DP (Butscher et al., 2011). The first published paper on TE scaffolds by 3DP was reported by Kim et al (Kim et al., 1998) who used a mixture of poly(lactic-co-glycolic acid) (PLGA) and $\mathrm{NaCl}$ as powder bed. By employing a 
solvent to bind the polymeric particles, uniformly distributed pore channels with a size of $800 \mu \mathrm{m}$ were obtained. After salt leaching, the structural elements presented pores with a size in the range 45 to $150 \mu \mathrm{m}$. During co-culture experiments employing hepatocytes and non-parenchymal cells, good cell attachment and albumin synthesis in both static and dynamic conditions were observed.

Natural polymers have been also proposed for scaffold fabrication by 3DP. For instance, starch was combined with dextran and gelatin to produce scaffolds using water as binder (Lam et al., 2002). However, these starch-based scaffolds presented limited structural integrity and low mechanical properties after drying at $100^{\circ} \mathrm{C}$. Slight improvements of the mechanical properties were achieved by infiltration of the scaffolds with a PLLA/PCL polymeric solution.

Bioactive ceramics, such as HA, bioactive glasses and tricalcium phosphates (TCP) are the most common materials used for scaffold production using 3DP technique (Leukers et al., 2005, Seitz et al., 2005, Meszaros et al., 2011, Tarafder et al., 2012). $\beta$-TCP bone fillers, produced by a patented 3DP technique known as Theriform, were one of the first medical products fabricated by an AM technique (Donald et al., 2002). The combination of different ceramic materials such as TCP and tetracalcium phosphate (TTCP) was investigated for the development of drug release matrices (Gbureck et al., 2007). Generally post-processing steps (e.g. sintering) are needed to improve implant mechanical properties (Butscher et al., 2011). In order to enhance the binding of ceramic particles, a 3DP technique involving the processing of a mixture of polymer and ceramic particles and the elimination of the polymer phase after sintering was investigated (Shanjani et al., 2010). Several types of polymeric powders acting as binder were investigated. For instance, starch was blended with HA particles and 
processed employing an aqueous binder (Will et al., 2008). A further study proposed the processing of poly(vinyl alcohol)/tricalcium polyphosphate (PVA/TCP) blends in combination with an aqueous binder (Shanjani et al., 2010).

The major disadvantage of 3DP technique is the shrinking of the scaffolds upon the sintering step that can cause distortions and fracture of the models (Shanjani et al., 2010). In addition, similarly to what observed in scaffolds by SLS, residual non-bound material can be found in complex geometries and the surface can present high roughness (Butscher et al., 2011).

\section{Melt-Extrusion Based Techniques}

Fused Deposition Modeling (FDM) is a commercially available AM technique, originally developed in 1992 for the rapid manufacturing of prototypes for industry (Crump, 1992), which is based on the extrusion of a polymeric filament through a heated nozzle (Figure 3d). Two independent extrusion nozzles can be used to deposit different polymeric materials, one usually employed as support material and the other one to produce the $3 \mathrm{D}$ object. The polymeric filament is supplied to the extrusion nozzle by means of drive wheels and the polymer melt is continuously deposited on a construction platform. The computer-controlled motion of the extrusion head and of the construction platform allows for the deposit of the molten filament with a predefined pattern (raster, contour and combination of both). After the fabrication of each layer, the platform moves downwards and the layer-upon-layer process is performed until the 3D object is obtained.

The possibility of producing TE scaffolds by FDM was firstly explored by Hutmacher et al (Hutmacher, 2000) who reported the production of PCL or PCL/HA composite scaffolds with different pore architecture, pore size and porosity. PCL scaffolds showed 
to support the in vitro proliferation, differentiation and ECM production of primary human fibroblasts and periosteal cells (Hutmacher et al., 2001). In vivo trials on a $2 \times 2$ cm orbit defect created surgically on a Yorkshire pig model using PCL scaffolds prepared by FDM showed that the formation of new bone reached $14.1 \%$ after three months (Rohner et al., 2003). A clinical pilot study for cranioplasty on five patients employing PCL plug scaffolds fabricated by FDM showed that after twelve months the implants were well integrated in the surrounding calvarial bone with new bone filling the porous space (Schantz et al., 2006). After that, PCL scaffolds produced by FDM were approved by FDA for craniofacial applications (Osteopore International: www.osteopore.com.sg) and are currently marketed by Osteopore International in the form of thin interwoven meshes $\left(\right.$ Osteomesh $^{\mathrm{TM}}$ ) or 3D implants (Osteoplug $\left.{ }^{\mathrm{TM}}\right)$. A study reported on the implantation of Osteoplug ${ }^{\mathrm{TM}}$ scaffolds into burr holes of twelve patients treated for a chronic subdural haematoma. The scaffolds showed good osteointegration into the surrounding calvarial bone and there were no adverse events in all patients, with a mean follow-up of 16 months (Low et al., 2009).

Biphasic constructs comprising a PCL cartilage scaffold and a PCL/TCP osseous matrix produced by FDM were recently investigated for the in vivo regeneration of osteochondral defects (Ho et al., 2010). After implantation into critically sized osteochondral defects in pigs, mesenchymal stem cells (MSCs)-seeded biphasic constructs coupled with an electrospun PCL/collagen membrane, acting as a barrier to prevent cell leakage, showed bone ingrowth and remodelling as well as cartilaginous repair with functional tissue restoration and low occurrence of fibrocartilage. In addition, PCL/TCP scaffolds fabricated by FDM were shown to be able to support in vitro human MSCs proliferation and osteogenic differentiation, and human 
MSCs/scaffold constructs were implanted in nude rat critical-sized femoral defects leading to cell survival in the defect site for up to 3 weeks post-transplantation, even if only $50 \%$ of the femoral defects responded favorably as determined by new bone volume (Rai et al., 2010).

PCL scaffolds by FDM were also investigated in comparison with polyurethane sponges for the engineering of adipose tissue showing in vivo angiogenesis, fibrous tissue formation and adipogenesis after 2 and 4 weeks of implantation in nude mice (Wiggenhauser et al., 2011).

FDM technique has given very promising preclinical and clinical results, although its employment is yet limited to few thermoplastic polymers. Other melt-extrusion based techniques have been developed in order to process a wider range of polymeric materials in diverse forms (e.g. pellet, powder), reducing the quantities of raw material used.

Three-Dimensional Fiber deposition (3DF) technique, also called 3D plotting, was originally developed by Landers et al for the production of hydrogel scaffolds (Landers and Mülhaupt, 2000), but was subsequently employed for producing scaffolds from a polymer melt using a deposition system composed of a heating jacket wrapping the cartridge containing the polymer. By applying a gas pressure, the molten polymer is forced through a nozzle and deposited selectively by means of an X-Y-Z moving arm. EnvisionTEC GmbH is currently marketing a 3DF system with the trademark 3DBioplotter $^{\circledR}$ (Envisiontec: www.envisiontec.com/index.php?page=news\&id=17).

Gloria et al (Gloria et al., 2009) recently reviewed the potential and challenges of 3DF to create multifunctional and tailor-made TE scaffolds. Poly(ethylene oxideterephthalate) and poly(butylene terephthalate) (PEOT/PBT) block copolymers 
scaffolds produced by 3DF were investigated for cartilage regeneration purposes (Moroni et al., 2006). By changing scaffold porosity, fiber deposition and fiber orientation, the viscoelastic properties of this kind of scaffolds could be modulated to accomplish mechanical requirements for tailored tissue engineered applications. Moreover, combining an integrated non-woven electrospun microstructure with a periodical 3DF macrostructure allowed to obtain a multi-scale PEOT/PBT scaffold with enhanced biological performance in terms of chondrocytes adhesion, proliferation, morphology and ECM production (Moroni et al., 2008). Recently, PEOT/PBT scaffolds by $3 \mathrm{DF}$ were tested in vivo in comparison with analogous scaffolds fabricated by compression molding/salt leaching (Emans et al., 2012). Following 3 weeks of in vitro culturing in combination with allogenic chondrocytes, they were implanted in osteochondral defects of skeletally mature rabbits showing after three months improved cartilage repair compared to compression molded scaffolds. 3D hybrid structures composed of a starch/PCL blend tubular scaffold, produced by 3DF and injected with gellan gum in the central hollow area, were investigated for spinal cord injury repair showing good in vitro compatibility with oligodendrocyte-like cells, olfactory ensheathing cells and Schwann cells (Silva et al., 2010, Silva et al., 2011). Moreover, preliminary in vivo studies, conducted in a hemisection rat spinal cord injury model, revealed that the hybrid scaffolds were well integrated within the injury and did not trigger any chronic inflammatory processes (Silva et al., 2011). A further study showed that by changing the structure of this kind of scaffolds, in terms of pore size and pore size gradients, it was possible to vary scaffold mechanical properties as well as cell seeding efficiency and cell distribution within the scaffold (Sobral et al., 2011). Four types of PCL scaffold architectures were recently investigated in vivo using a rat iliac 
crest defect model (Yilgor et al., 2012). New bone formation was higher on the scaffolds with higher pore volume for tissue ingrowth, and the healing of the bone defects was further enhanced by combining the largest pore volume scaffolds with bone morphogenetic proteins.

Precision Extrusion Deposition (PED) is a melt-extrusion AM technique based on a screw extruder enabling the processing of polymer pellets for the controlled deposition of a melt filament. PCL scaffolds with high precision at the micro-scale as well as repeatability of the architecture were developed employing this technique (Wang et al., 2004, Shor et al., 2009). Osteoblast-seeded PCL scaffolds showed in vivo osseous ingrowth after subcutaneous implantation in nude mice (Shor et al., 2009). Morevoer, the introduction of an assisting cooling device, which increases the working extrusion temperature up to $250^{\circ} \mathrm{C}$, allowed expanding PED library of polymers as demonstrated by producing 3D scaffolds made of PGA (melting point of $200^{\circ} \mathrm{C}$ ) (Hamid et al., 2011).

Bioextruder is an innovative AM system comprising two different deposition systems for simultaneously processing polymer melts and solutions/suspensions to produce multi-material scaffolds incorporating cells and bioactive agents (Mota et al., 2009). The melt-extrusion head is composed of a gas pressurized container connected to a screw extruder allowing an accurate control of polymer melt deposition. This system was successfully employed to produce PCL scaffolds with different pore size and architecture showing that it is possible to control scaffold porosity by varying different processing parameters, such as screw rotation velocity and deposition velocity (Domingos et al., 2009, Domingos et al., 2010, Domingos et al., 2011). 
Bioscaffolder $^{\mathrm{TM}}$ (SysEng) is a commercially available AM machine that comprises two different dispense head types: a syringe pump for gels, pastes or slurries, and a meltextrusion head composed of a gas pressurized reservoir coupled with an auger screw system for thermoplastics (Ragaert et al., 2010). This machine was recently employed to illustrate the lack of scaffold reproducibility in melt-extrusion based AM techniques when working with degradation sensitive polymers, such as poly(lactic acid) (PLA). PCL scaffolds produced by means of Bioscaffolder ${ }^{\mathrm{TM}}$ and embedded with a polyelectrolyte complex matrix of hyaluronic acid, methylated collagen and terpolymer showed in vitro higher seeding efficiency, more homogeneous cell distribution and higher differentiation towards osteoblastic phenotype of human MSCs when compared to naked PCL scaffolds (Chen et al., 2011).

\section{Solution/Slurry Extrusion Based Techniques}

Different AM techniques involving the processing of a polymeric solution or ceramic slurry have been developed in the last years. They don't require the use of high temperature thus avoiding concerns associated with temperature degradation of polymers and bioactive agents, even if they often involve the use of organic solvents that, if not completely removed, may compromise the biocompatibility of the scaffold and alter incorporated bioactive factors. In addition to the previously mentioned AM systems (i.e. Bioplotter®, Bioscaffolder and Bioextruder) that comprise several extrusion/deposition systems, other approaches were developed for the production of scaffolds by processing solutions or slurries.

Pressure assisted microsyringe (PAM) is an AM technique employing a micropositioning system with a pressure-activated microsyringe equipped with a finebore exit needle. It enables the controlled deposition of an extruded polymeric solution 
that, after solvent evaporation, leads to the formation of a predesigned microstructure (Vozzi et al., 2002, Vozzi et al., 2003). The possibility of producing 3D structures made of different biodegradable polymers, such as PCL, PLLA or PLGA, by means of PAM technique has been shown by different studies (Vozzi et al., 2002, Vozzi et al., 2003). A piston-assisted microsyringe (PAM2) system was recently developed for low-shear stress extrusion of viscous hydrogel solutions containing cells, as demonstrated by a study employing solutions of sodium alginate incorporating hepatocytes (Tirella et al., 2011b).

Low-temperature Deposition Manufacturing (LDM) is a technique exploiting a controlled cooling chamber that allows to maintain a low temperature along the deposition process of a polymeric slurry (Xiong et al., 2002). After the 3D structure is built up layer-by-layer, the solvent is usually removed by freeze drying. PLLA/TCP slurries were deposited using a computer-controlled LDM system to produce composite scaffolds for bone repair achieving a fairly good control over porosity and a microporosity of $5 \mu \mathrm{m}$ in the structure strands as consequence of the freeze drying step. In vivo trials, implanting the scaffolds on canine radius, showed good biocompatibility and good bone regeneration after 24 weeks. A recent in vitro study on composite scaffolds by LDM showed that PLGA/pearl scaffolds support the adhesion, proliferation and differentiation into osteoblasts of rabbit MSCs isolated from femoral crest (Xu et al., 2010). A similar AM system equipped with a cryogenic cooled construction platform was employed for the fabrication of natural polymer scaffolds (Kim et al., 2009, Kim et al., 2011). Using this technique, collagen scaffolds with controlled porous structure and limited shrinkage were developed for skin TE (Kim et al., 2009). In order to increase structural stability, a hybrid scaffold composed of an outer collagen shell and 
an inner alginate core was designed and successfully fabricated showing enhanced mechanical properties and rapid vascularisation when tested in vivo after implantation in mice as dermal substitute (Kim et al., 2011).

Recent studies investigated a new approach for natural polymer scaffolds fabrication involving the patterned extrusion of a photo polymerizable hydrogel ink (composed of physically entangled polymer chains dissolved in a monomer solution) under UV light exposition. Using this technique, 3D hydrogel scaffolds were developed by processing polymeric inks composed of poly(acrylamide) chains in a photopolymerizable acrylamide solution (Barry et al., 2009), or poly(2-hydroxyethyl methacrylate) chains dissolved in a solution of its monomer (Hanson Shepherd et al., 2011).

Robocasting, also referred to as direct-write assembly, is an AM technique allowing to fabricate ceramic (e.g. $\beta$-TCP or HA) scaffolds with tailored geometry and porosity using water-based highly concentrated colloidal suspensions with minimal organic content that are extruded trough a nozzle inside a non-wetting oil bath (Miranda et al., 2006, Miranda et al., 2008). Compressive strength of $\beta$-TCP scaffolds produced by robocasting was improved by infiltration of melted PCL or PLA into the porous structure (Martinez-Vazquez et al., 2010). An alternative method to produce polymer/ceramic scaffolds with high inorganic content $(70 \mathrm{wt} \%)$ involved the processing of an HA suspension in either PLA or PCL solution (Russias et al., 2007). In this case the high viscosity of the processed slurry allowed avoiding the utilization of the oil bath and no sintering step was performed due to the fast evaporation of the solvent. Ceramic inks composed of HA, $\beta$-TCP or biphasic HA/ $\beta$-TCP suspension in Pluronic ${ }^{\circledR}$ F-127 aqueous solutions were used to produce scaffolds with different microporosity and mechanical properties depending on the copolymer content and the 
granulometry of the ceramic powder (Franco et al., 2010). HA and $\beta$-TCP scaffolds produced by robocasting were also combined with BMP-2 growth factor, to improve osteoinductivity, showing in vivo bone regeneration to promotion after implantation in pig model (Abarrategi et al., 2012). Suspensions of a bioactive glass (6P53B) in Pluronic ${ }^{\circledR}$ F-127 aqueous solution was employed to fabricate scaffolds that after sintering presented compressive strength suitable for bone load-bearing applications $(\mathrm{Fu}$ et al., 2011).

\section{Tissue and Organ Printing}

The past years have seen the rapid development of a new TE strategy based on AM principles, commonly referred to as tissue or organ printing, which is aimed at the development of cell-laden constructs by employing automated technologies and taking advantage from the self-organizing properties of cells and tissues (Mironov et al., 2003). It involves the layer-by-layer deposition of cells and bioactive agents, usually in the form of self-assembling tissue building blocks obtained by employing hydrogels to form biopaper or bio-ink (Mironov et al., 2007, Norotte et al., 2009). The aim is to deliver scaffolding materials, living cells, nutrients, growth factors, drugs and other required chemicals with a precise control over deposition's time, position and amount, in order to obtain controlled microenvironments for the development of customized living tissue engineered constructs (Boland et al., 2006). An increasing number of research activities dedicated to this approach have led to the development of lab-scale and commercially available manufacturing devices based on different organ biofabrication technologies, such as thermal or piezoelectric inkjet printing, 3D printing by mechanical dispensing of cells and laser-assisted bioprinting (Guillemot et al., 2011, Mironov et al., 2011). 
Thermal ink-jet technologies have been explored for the delivery of controlled volumes of delicate biological systems to defined 3D locations (Boland et al., 2006, Boland et al., 2007). As an example, aortal endothelial cells in combination with a crosslinking calcium chloride solution were deposited layer-by-layer using a modified HP Deskjet printer on top of a platform containing an alginate solution, proving that cells are able to attach and migrate in the resulting microchannel architecture (Boland et al., 2006). Using the same drop-on-demand process, micron-sized fibrin channels were developed by employing human microvascular endothelial cell suspensions mixed with thrombin as bio-ink and a fibrinogen solution as biopaper substrate (Cui and Boland, 2009). A recent study involving Olivetti BioJet system, which employs a thermal inkjet cartridge, investigated the velocity profile and the mechanical load acting on a droplet during the cell printing process (Tirella et al., 2011a). Moreover, by testing different collection substrates, it was demonstrated that the impact forces acting on the droplet during the deposition process, conditioning cell viability, are highly dependent on substrate stiffness.

A drop-on-demand inkjet printing system based on a piezoelectric membrane was investigated to deliver suspensions of human fibroblast cells showing that the amplitude of the pulse used to excite the piezoelectric actuator has a small influence on cell survival rates (Saunders et al., 2008). However, cell agglomeration or sedimentation inside the deposition cartridge affected the printing performance.

Laser-assisted BioPrinting (LaBP) techniques have emerged as an alternative approach to cartridge-based system for the production of tissue engineered substitutes (Barron et al., 2004, Guillemot et al., 2010, Guillotin et al., 2010, Catros et al., 2011, Gruene et al., 2011, Koch et al., 2012). These techniques are based on laser pulses focussed onto a 
metallic absorption layer that evaporates at the focal points leading to the generation, on the subjacent layer of cell-containing hydrogel precursor, of a jet propelling toward a lower collector hydrogel slide. This technology is capable of positioning high cell densities (up to $10^{8}$ cells $/ \mathrm{mL}$ ) and small volumes (down to a few hundred femtoliters) of cell suspensions with high resolution for the manufacturing of 3D living constructs with complex architecture (Ringeisen et al., 2006, Gruene et al., 2011, Koch et al., 2012). For instance, a recent study employed a LaBP system to reproduce the layered configuration of skin by printing layer-by-layer murine fibroblasts and human keratinocytes embedded in collagen (Koch et al., 2012). BioLPTM (biological laser printing) were used to print a variety of cell types including osteosarcoma (Barron et al., 2004), olfactory ensheathing cells (Othon et al., 2008), carcinoma cells (Ringeisen et al., 2004), bovine aortic endothelial cells (BAEC) (Chen et al., 2006), human umbilical vein smooth muscle cell and human umbilical vein endothelial cells (HUVEC) (Wu and Ringeisen, 2010). In addition, HUVEC were recently printed by BioLPTM onto hybrid biopapers that contained bilayers of PLGA and collagen type I to build 3D vascularized tissues, resulting in good cell infiltration and survival in the compound multilayer constructs (Pirlo et al., 2012).

As previously described, Bioscaffolder ${ }^{\mathrm{TM}}$ comprises, besides a melt-extrusion system, a pressure- or volume-controlled dispenser allowing the accurate deposition of polymeric solutions and gels. Indeed, it was recently employed for the processing of multipotent stromal cells mixed with alginate to produce porous and solid hydrogel scaffolds with cells homogeneously dispersed throughout the construct that once implanted subcutaneously in immunodeficient mice resulted in ingrowth of vascularized tissue (Fedorovich et al., 2011a). A further study showed the suitability of Bioscaffolder ${ }^{\mathrm{TM}}$ to 
print intricate porous constructs containing two different cell types (endothelial progenitors and multipotent stromal cells) that retained heterogeneous cell organization after in vivo implantation, leading to blood vessels formation in the endothelial progenitor cell-laden part and to bone formation in the multipotent stromal cell-laden part (Fedorovich et al., 2011b).

The recent explosion of interest in organ printing has led to the development of other types of laboratory available robotic systems for the production of cell-laden living constructs mimicking the structure of different tissues, such as blood vessels (Norotte $e t$ al., 2009, Skardal et al., 2010), nerves (Francoise et al., 2012), skin (Lee et al., 2009, Koch et al., 2012) and bone (Fedorovich et al., 2011a, Fedorovich et al., 2011b). However, as pointed out by Mironov et al. (Mironov et al., 2011), the use of robotic bioprinters alone is not sufficient for the development of large industrial scale organ biofabrication. Anyhow, the progress in tissue spheroid biofabrication, the emergence of commercial bioprinters and the development of perfusion bioreactors suitable for organ printing open new perspectives for the design of fully integrated organ biofabrication lines, necessary for the commercial translation of organ printing technology.

\section{Innovative AM Equipments}

To overcome the limitations of the commercially available systems for TE scaffolds production, several research groups and specialized companies have developed customized equipments that can meet different requirements in terms of scaffold material, internal architecture and external shape. Some of the new developed techniques are constantly being adapted to offer the possibility of processing a wider range of materials improving the performance of the manufactured structures. One example of a commercially available equipment that is continuously being improved is 
the 3D-Bioplotter ${ }^{\circledR}$ system that is nowadays in its fourth generation (Envisiontec: www.envisiontec.com/index.php?page=news\&id=17).

Open source AM systems have generated growing interest within the scientific community offering adaptable tool for new solutions in the manufacturing of customized TE scaffolds. As an example, Fab@home is an open-source, open architecture and low cost rapid prototyping system, developed originally for the production of end-user prototypes (Malone and Lipson, 2007). It is based on worldwide collaboration of users to develop customized AM systems with innovative solutions comprising new extrusion and/or deposition heads that allow for the processing of novel and multiple materials in the course of scaffold fabrication. Recently, Cohen et al used a Fab@home system for the development of alginate hydrogel scaffolds for cartilage replacements (Cohen et al., 2011).

A fully automated bench-top manufacturing system called BioCell Printing for the integrated, continuous and fully automated production and in vitro dynamic culture of tissue engineering constructs was recently designed (Bártolo et al., 2011). This system integrates four phases (scaffold fabrication, sterilization, cell seeding and dynamic cell culture on bioreactor) of the manufacturing of tissue engineered constructs in order to reduce risks of contamination that might occur in separated phases of the process and to reduce the manufacturing time.

A new research trend aims at direct printing in vivo and in situ of cells, biomaterials or their combinations. The first study using this approach involved laser printing of HA nanoparticles into mouse calvaria defect of critical size, resulting in heterogeneous effect on bone formation from one sample to another (Keriquel et al., 2010). Another approach recently developed comprises the printing in situ of skin directly on a wound 
by means of a cartridge-based system (Binder et al., 2011). Robotic delivery systems, comprising optical detector to collect data from the wounded region and computer-aided data processing software to calculate the deposition pattern, were developed and patented for in situ ink-jet printing of cells and biomaterials (Yoo et al., 2011).

\section{Conclusive Remarks and Future Perspectives}

A wide range of AM techniques based on various fabrication strategies have been proposed in the last ten years for the development of TE scaffolds with different composition and internal architecture. The increasing interest in these techniques is due to the possibility of achieving good reproducibility and control over scaffold microstructure and shape, and thus of developing customized tissue engineered constructs that can meet specific requirements in terms of pore size, geometry and interconnectivity, as well as in terms of anatomical shape and size. In addition, in comparison with conventional scaffold fabrication techniques, they allow for high automation of the manufacturing process with a subsequent reduction of human intervention and enhancement of production rate.

Progress in AM technology has led to the development of laboratory prototype equipments that in some cases have been finding commercial translation into advanced and versatile systems for TE scaffolds production. The new frontier is the design of fully integrated AM lines for the automation of the whole process necessary to fabricate on an industrial scale ready to use tissue engineered constructs. The idea is to integrate automated robotic devices carrying out different stages in the development of engineered tissues, from pre-processing steps (medical imaging, cells harvesting from patient, etc.) to tissue maturation by dynamic cell culturing into bioreactors. 
The rapid manufacturing of customized tissue engineered constructs tailored on specific patient requirements, besides allowing fast production of large quantities of samples for high throughput TE studies, can enhance clinical routine procedures in terms of readily available products better meeting routine surgical needs.

\section{Acknowledgments}

The present review paper on Additive Manufacturing techniques is intended to be as a follow-up of the scientific and technical inputs stemming from the NoE Expertissues NMP3-CT-2004-500283 and Hyanji Scaffold PIRSES-GA-2008-230791.

\section{References}

Abarrategi A, Moreno-Vicente C, Martinez-Vazquez FJ, Civantos A, Ramos V, SanzCasado JV, Martinez-Corria R, Perera FH, Mulero F, Miranda P et al, 2012, Biological properties of solid free form designed ceramic scaffolds with BMP-2: in vitro and in vivo evaluation, PloS one, 7(3): e34117

Almeida HA, Bártolo PJ, 2010, Virtual topological optimisation of scaffolds for rapid prototyping, Med Eng Phys, 32(7): 775-782

Arcaute K, Mann B, Wicker R, 2006, Stereolithography of three-dimensional bioactive poly(ethylene glycol) constructs with encapsulated cells, Ann Biomed Eng, 34(9): 1429-1441

ASTM Standard F2792 - 12a, 2012, Standard Terminology for Additive Manufacturing Technologies, DOI: 10.1520/F2792-12A, www.astm.org

Barron JA, Wu P, Ladouceur HD, Ringeisen BR, 2004, Biological laser printing: a novel technique for creating heterogeneous 3-dimensional cell patterns, Biomed Microdevices, 6(2): 139-147

Barry RA, Shepherd RF, Hanson JN, Nuzzo RG, Wiltzius P, Lewis JA, 2009, Directwrite assembly of 3D hydrogel scaffolds for guided cell growth, Adv Mater, 21(23): 2407-2410

Bártolo P, Domingos M, Gloria A, Ciurana J, 2011, BioCell printing: Integrated automated assembly system for tissue engineering constructs, CIRP Ann Manuf Technol, 60(1): 271-274

Bertsch A, Renaud P. 2011, Microstereolithography in Stereolithography: Materials, Processes and Applications, eds. Bártolo P, Springer, NY; 81-112.

Binder KW, Allen AJ, Yoo JJ, Atala A, 2011, Drop-on-demand inkjet bioprinting: A primer, Gene Ther Regul, 06(01): 33-49

Boland T, Tao X, Damon BJ, Manley B, Kesari P, Jalota S, Bhaduri S, 2007, Drop-ondemand printing of cells and materials for designer tissue constructs, Mater Sci Eng C Mater Biol Appl, 27(3): 372-376

Boland T, Xu T, Damon B, Cui X, 2006, Application of inkjet printing to tissue engineering, Biotechnol J, 1(9): 910-917 
Butscher A, Bohner M, Hofmann S, Gauckler L, Muller R, 2011, Structural and material approaches to bone tissue engineering in powder-based threedimensional printing, Acta Biomater, 7(3): 907-920

Catros S, Fricain JC, Guillotin B, Pippenger B, Bareille R, Remy M, Lebraud E, Desbat B, Amédée J, Guillemot F, 2011, Laser-assisted bioprinting for creating ondemand patterns of human osteoprogenitor cells and nano-hydroxyapatite, Biofabrication, 3(2): 025001

Chen CY, Barron JA, Ringeisen BR, 2006, Cell patterning without chemical surface modification: Cell-cell interactions between printed bovine aortic endothelial cells (BAEC) on a homogeneous cell-adherent hydrogel, Appl Surf Sci, 252(24): 8641-8645

Chen M, Le DQS, Baatrup A, Nygaard JV, Hein S, Bjerre L, Kassem M, Zou X, Bünger C, 2011, Self-assembled composite matrix in a hierarchical 3-D scaffold for bone tissue engineering, Acta Biomater, 7(5): 2244-2255

Choi J-W, Kim H-C, Wicker R, 2011, Multi-material stereolithography, J Mater Process Technol, 211(3): 318-328

Choi J-W, Wicker R, Lee S-H, Choi K-H, Ha C-S, Chung I, 2009, Fabrication of 3D biocompatible/biodegradable micro-scaffolds using dynamic mask projection microstereolithography, J Mater Process Technol, 209(15-16): 5494-5503

Chu TMG, Halloran JW, Hollister SJ, Feinberg SE, 2001, Hydroxyapatite implants with designed internal architecture, J Mater Sci Mater Med, 12(6): 471-478

Ciardelli G, Chiono V, Vozzi G, Pracella M, Ahluwalia A, Barbani N, Cristallini C, Giusti P, 2005, Blends of poly-(epsilon-caprolactone) and polysaccharides in tissue engineering applications, Biomacromolecules, 6(4): 1961-1976

Claeyssens F, Hasan EA, Gaidukeviciute A, Achilleos DS, Ranella A, Reinhardt C, Ovsianikov A, Shizhou X, Fotakis C, Vamvakaki M et al, 2009, Threedimensional biodegradable structures fabricated by two-photon polymerization, Langmuir, 25(5): 3219-3223

Cohen DL, Lo W, Tsavaris A, Peng D, Lipson H, Bonassar LJ, 2011, Increased mixing improves hydrogel homogeneity and quality of three-dimensional printed constructs, Tissue Eng Part C Methods, 17(2): 239-248

Crump SS, 1992, Apparatus and method for creating three-dimensional objects, US Patent No. 5121329.

Cui X, Boland T, 2009, Human microvasculature fabrication using thermal inkjet printing technology, Biomaterials, 30(31): 6221-6227

Deckard CR, 1989, Method and apparatus for producing parts by selective sintering, US Patent No. 5017753.

Dhariwala B, Hunt E, Boland T, 2004, Rapid prototyping of tissue-engineering constructs, using photopolymerizable hydrogels and stereolithography, Tissue Eng, 10(9-10): 1316-1322

Domingos M, Chiellini F, Cometa S, De Giglio E, Grillo-Fernandes E, Bártolo P, Chiellini E, 2010, Evaluation of in vitro degradation of PCL scaffolds fabricated via BioExtrusion. Part 1: Influence of the degradation environment, Virtual Phys Prototyping, 5(2): 65-73

Domingos M, Dinucci D, Cometa S, Alderighi M, Bartolo PJ, Chiellini F, 2009, Polycaprolactone scaffolds fabricated via bioextrusion for tissue engineering applications, Int J Biomater, 2009: 239643 
Domingos MA, Chiellini F, Gloria A, Ambrosio L, Bártolo PJ, Chiellini E, 2011, Effect of process parameters on the morphological and mechanical properties of 3D Bioextruded poly (e-caprolactone) scaffolds, Rapid Prototyping J, 18(1): 6

Donald M, Chen-Chao W, Charles R. 2002, TheriForm Technology in ModifiedRelease Drug Delivery Technology, eds. Rathbone MJ, Hadgraft J, Roberts MS, Informa Healthcare, 77-87.

Duan B, Cheung WL, Wang M, 2011a, Optimized fabrication of Ca-P/PHBV nanocomposite scaffolds via selective laser sintering for bone tissue engineering, 3(1):

Duan B, Cheung WL, Wang M, 2011b, Optimized fabrication of Ca-P/PHBV nanocomposite scaffolds via selective laser sintering for bone tissue engineering, Biofabrication, 3(1): 015001

Duan B, Wang M, 2010a, Customized Ca-P/PHBV nanocomposite scaffolds for bone tissue engineering: design, fabrication, surface modification and sustained release of growth factor, $J R$ Soc Interface, 7(SUPPL. 5): S615-S629

Duan B, Wang M, 2010b, Encapsulation and release of biomolecules from Ca-P/PHBV nanocomposite microspheres and three-dimensional scaffolds fabricated by selective laser sintering, Polym Degrad Stab, 95(9): 1655-1664

Duan B, Wang M, Li ZY, Chan WC, Lu WW, 2011c, Surface modification of threedimensional Ca-P/PHBV nanocomposite scaffolds by physical entrapment of gelatin and its in vitro biological evaluation, Front Mater Sci China, 5(1): 57-68

Duan B, Wang M, Zhou WY, Cheung WL, Li ZY, Lu WW, 2010, Three-dimensional nanocomposite scaffolds fabricated via selective laser sintering for bone tissue engineering, Acta Biomater, 6(12): 4495-4505

Elomaa L, Teixeira S, Hakala R, Korhonen H, Grijpma DW, Seppala JV, 2011, Preparation of poly(epsilon-caprolactone)-based tissue engineering scaffolds by stereolithography, Acta Biomater, 7(11): 3850-3856

Emans PJ, Jansen EJP, van Iersel D, Welting TJM, Woodfield TBF, Bulstra SK, Riesle J, van Rhijn LW, Kuijer R, 2012, Tissue-engineered constructs: the effect of scaffold architecture in osteochondral repair, J Tissue Eng Regen Med: DOI: 10.1002/term. 1477

Envisiontec: www.envisiontec.com/index.php?page $=$ news\&id=17

Eosoly S, Brabazon D, Lohfeld S, Looney L, 2010, Selective laser sintering of hydroxyapatite/poly-epsilon-caprolactone scaffolds, Acta Biomater, 6(7): 25112517

Fedorovich NE, Alblas J, de Wijn JR, Hennink WE, Verbout AJ, Dhert WJ, 2007, Hydrogels as extracellular matrices for skeletal tissue engineering: state-of-theart and novel application in organ printing, Tissue Eng, 13(8): 1905-1925

Fedorovich NE, Kuipers E, Gawlitta D, Dhert WJA, Alblas J, 2011a, Scaffold porosity and oxygenation of printed hydrogel constructs affect functionality of embedded osteogenic progenitors, Tissue engineering Part A, 17(19-20): 2473-2486

Fedorovich NE, Wijnberg HM, Dhert WJA, Alblas J, 2011b, Distinct tissue formation by heterogeneous printing of osteo-and endothelial progenitor cells, Tissue engineering Part A, 17(15-16): 2113-2121

Franco J, Hunger P, Launey ME, Tomsia AP, Saiz E, 2010, Direct write assembly of calcium phosphate scaffolds using a water-based hydrogel, Acta Biomater, 6(1): 218-228 
Francoise M, Karoly J, Chirag K, Benjamin S, Scott D, Bradley H, Stephen C, Forgacs $\mathrm{G}$, 2012, Toward engineering functional organ modules by additive manufacturing, Biofabrication, 4(2): 022001

Fu Q, Saiz E, Tomsia AP, 2011, Direct ink writing of highly porous and strong glass scaffolds for load-bearing bone defects repair and regeneration, Acta Biomater, 7(10): 3547-3554

Gabbrielli R, Turner I, Bowen CR, 2008, Development of modelling methods for materials to be used as bone substitutes, Key Eng Mater, 361: 903-906

Gbureck U, Vorndran E, Muller FA, Barralet JE, 2007, Low temperature direct 3D printed bioceramics and biocomposites as drug release matrices, $J$ Control Release, 122(2): 173-180

Gloria A, Russo T, De Santis R, Ambrosio L, 2009, 3D fiber deposition technique to make multifunctional and tailor-made scaffolds for tissue engineering applications, J Appl Biomater Biomech, 7(3): 141-152

Gruene M, Pflaum M, Hess C, Diamantouros S, Schlie S, Deiwick A, Koch L, Wilhelmi M, Jockenhoevel S, Haverich A et al, 2011, Laser printing of three-dimensional multicellular arrays for studies of cell-cell and cell-environment interactions, Tissue Eng Part C Methods, 17(10): 973-982

Guillemot F, Guillotin B, Fontaine A, Ali M, Catros S, Kériquel V, Fricain JC, Rémy M, Bareille R, Amédée-Vilamitjana J, 2011, Laser-assisted bioprinting to deal with tissue complexity in regenerative medicine, MRS Bull, 36(12): 1015-1019

Guillemot F, Souquet A, Catros S, Guillotin B, Lopez J, Faucon M, Pippenger B, Bareille R, Rémy M, Bellance S et al, 2010, High-throughput laser printing of cells and biomaterials for tissue engineering, Acta Biomater, 6(7): 2494-2500

Guillotin B, Souquet A, Catros S, Duocastella M, Pippenger B, Bellance S, Bareille R, Rémy M, Bordenave L, Amédée j J et al, 2010, Laser assisted bioprinting of engineered tissue with high cell density and microscale organization, Biomaterials, 31(28): 7250-7256

Hamid Q, Snyder J, Wang C, Timmer M, Hammer J, Guceri S, Sun W, 2011, Fabrication of three-dimensional scaffolds using precision extrusion deposition with an assisted cooling device, Biofabrication, 3(3): 034109

Hanson Shepherd JN, Parker ST, Shepherd RF, Gillette MU, Lewis JA, Nuzzo RG, 2011, 3D microperiodic hydrogel scaffolds for robust neuronal cultures, Adv Funct Mater, 21(1): 47-54

Hieu LC, Zlatov N, Sloten JV, Bohez E, Khanh L, Binh PH, Oris P, Toshev Y, 2005, Medical rapid prototyping applications and methods, Assem Autom, 25(4): 284292

Ho ST, Hutmacher DW, Ekaputra AK, Hitendra D, Hui JH, 2010, The evaluation of a biphasic osteochondral implant coupled with an electrospun membrane in a large animal model, Tissue engineering Part A, 16(4): 1123-1141

Hull CW, 1986, Apparatus for production of three-dimensional objects by stereolithography, US Patent No. 4575330.

Hull CW, 1990, Method for production of three-dimensional objects by stereolithography, US Patent No. 4929402.

Hutmacher DW, 2000, Scaffolds in tissue engineering bone and cartilage, Biomaterials, 21(24): 2529-2543 
Hutmacher DW, Schantz T, Zein I, Ng KW, Teoh SH, Tan KC, 2001, Mechanical properties and cell cultural response of polycaprolactone scaffolds designed and fabricated via fused deposition modeling, J Biomed Mater Res, 55(2): 203-216

Hutmacher DW, Sittinger M, Risbud MV, 2004, Scaffold-based tissue engineering: rationale for computer-aided design and solid free-form fabrication systems, Trends Biotechnol, 22(7): 354-362

Jansen J, Melchels FPW, Grijpma DW, Feijen J, 2008, Fumaric acid monoethyl esterfunctionalized poly(D,L-lactide)/N-vinyl-2-pyrrolidone resins for the preparation of tissue engineering scaffolds by stereolithography, Biomacromolecules, 10(2): 214-220

Karageorgiou V, Kaplan D, 2005, Porosity of 3D biomaterial scaffolds and osteogenesis, Biomaterials, 26(27): 5474-5491

Keriquel V, Guillemot F, Arnault I, Guillotin B, Miraux S, Amedee J, Fricain JC, Catros S, 2010, In vivo bioprinting for computer- and robotic-assisted medical intervention: preliminary study in mice, Biofabrication, 2(1): 014101

Kim G, Ahn S, Kim Y, Cho Y, Chun W, 2011, Coaxial structured collagen-alginate scaffolds: Fabrication, physical properties, and biomedical application for skin tissue regeneration, J Mater Chem, 21(17): 6165-6172

Kim G, Ahn S, Yoon H, Kim Y, Chun W, 2009, A cryogenic direct-plotting system for fabrication of $3 \mathrm{D}$ collagen scaffolds for tissue engineering, J Mater Chem, 19(46): 8817-8823

Kim SS, Utsunomiya H, Koski JA, Wu BM, Cima MJ, Sohn J, Mukai K, Griffith LG, Vacanti JP, 1998, Survival and function of hepatocytes on a novel threedimensional synthetic biodegradable polymer scaffold with an intrinsic network of channels, Ann Surg, 228(1): 8-13

Koch L, Deiwick A, Schlie S, Michael S, Gruene M, Coger V, Zychlinski D, Schambach A, Reimers K, Vogt PM et al, 2012, Skin tissue generation by laser cell printing, Biotechnol Bioeng:

Kodama H, 1981, Automatic method for fabricating a three-dimensional plastic model with photo-hardening polymer, Rev Sci Instrum, 52(11): 1770-1773

Krishna CRK, Ming CL, Gregory EH, Roger FB, Mariano V, 2011, Fabrication of 1393 bioactive glass scaffolds for bone tissue engineering using indirect selective laser sintering, Biofabrication, 3(2): 025004

Lam CXF, Mo XM, Teoh SH, Hutmacher DW, 2002, Scaffold development using 3D printing with a starch-based polymer, Mater Sci Eng C Mater Biol Appl, 20(12): $49-56$

Lan P, Lee J, Seol Y-J, Cho D-W, 2009, Development of 3D PPF/DEF scaffolds using micro-stereolithography and surface modification, J Mater Sci Mater Med, 20(1): 271-279

Landers R, Mülhaupt R, 2000, Desktop manufacturing of complex objects, prototypes and biomedical scaffolds by means of computer-assisted design combined with computer-guided 3D plotting of polymers and reactive oligomers, Macromol Mater Eng, 282(1): 17-21

Lee JW, Ahn G, Kim DS, Cho D-W, 2009, Development of nano- and microscale composite 3D scaffolds using PPF/DEF-HA and micro-stereolithography, Microelectron Eng, 86(4-6): 1465-1467 
Leong KF, Cheah CM, Chua CK, 2003, Solid freeform fabrication of three-dimensional scaffolds for engineering replacement tissues and organs, Biomaterials, 24(13): 2363-2378

Leukers B, Gülkan H, Irsen S, Milz S, Tille C, Schieker M, Seitz H, 2005, Hydroxyapatite scaffolds for bone tissue engineering made by 3D printing, $J$ Mater Sci Mater Med, 16(12): 1121-1124

Levy RA, Chu TM, Halloran JW, Feinberg SE, Hollister S, 1999, CT-generated porous hydroxyapatite orbital floor prosthesis as a prototype bioimplant, $J$ Neuroophthalmol, 19(2): 1522-1525

Low SW, Ng YJ, Yeo TT, Chou N, 2009, Use of Osteoplug polycaprolactone implants as novel burr-hole covers, Singapore medical journal, 50(8): 777-780

Lu Y, Mapili G, Suhali G, Chen S, Roy K, 2006, A digital micro-mirror device-based system for the microfabrication of complex, spatially patterned tissue engineering scaffolds, J Biomed Mater Res A, 77A(2): 396-405

Malone E, Lipson H, 2007, Fab@Home: the personal desktop fabricator kit, Rapid Prototyping J, 13(4): 245-255

Mano JF, Silva GA, Azevedo HS, Malafaya PB, Sousa RA, Silva SS, Boesel LF, Oliveira JM, Santos TC, Marques AP et al, 2007, Natural origin biodegradable systems in tissue engineering and regenerative medicine: present status and some moving trends, J R Soc Interface, 4(17): 999-1030

Martinez-Vazquez FJ, Perera FH, Miranda P, Pajares A, Guiberteau F, 2010, Improving the compressive strength of bioceramic robocast scaffolds by polymer infiltration, Acta Biomater, 6(11): 4361-4368

Melchels FP, Barradas AM, van Blitterswijk CA, de Boer J, Feijen J, Grijpma DW, 2010a, Effects of the architecture of tissue engineering scaffolds on cell seeding and culturing, Acta Biomater, 6(11): 4208-4217

Melchels FP, Feijen J, Grijpma DW, 2009, A poly(D,L-lactide) resin for the preparation of tissue engineering scaffolds by stereolithography, Biomaterials, 30(23-24): 3801-3809

Melchels FPW, Feijen J, Grijpma DW, 2010b, A review on stereolithography and its applications in biomedical engineering, Biomaterials, 31(24): 6121-6130

Meszaros R, Zhao R, Travitzky N, Fey T, Greil P, Wondraczek L, 2011, Threedimensional printing of a bioactive glass, Glass Technol-Part A, 52(4): 111-116

Miranda P, Pajares A, Saiz E, Tomsia AP, Guiberteau F, 2008, Mechanical properties of calcium phosphate scaffolds fabricated by robocasting, J Biomed Mater Res A, 85A(1): 218-227

Miranda P, Saiz E, Gryn K, Tomsia AP, 2006, Sintering and robocasting of $\beta$-tricalcium phosphate scaffolds for orthopaedic applications, Acta Biomater, 2(4): 457-466

Mironov V, Boland T, Trusk T, Forgacs G, Markwald RR, 2003, Organ printing: computer-aided jet-based 3D tissue engineering, Trends in Biotechnol, 21(4): $157-161$

Mironov V, Kasyanov V, Markwald RR, 2011, Organ printing: From bioprinter to organ biofabrication line, Curr Opin Biotechnol, 22(5): 667-673

Mironov V, Prestwich G, Forgacs G, 2007, Bioprinting living structures, J Mater Chem, 17(20): 2054-2060

Moroni L, de Wijn JR, van Blitterswijk CA, 2006, 3D fiber-deposited scaffolds for tissue engineering: influence of pores geometry and architecture on dynamic mechanical properties, Biomaterials, 27(7): 974-985 
Moroni L, Schotel R, Hamann D, de $\square$ Wijn JR, van $\square$ Blitterswijk CA, 2008, 3D FiberDeposited Electrospun Integrated Scaffolds Enhance Cartilage Tissue Formation, Adv Funct Mater, 18(1): 53-60

Mota C, Mateus A, Bártolo PJ, Almeida H, Ferreira N, 2009, Process and equipment for rapid fabrication through bioextrusion., Portuguese patent No.104247.

Mota C, Puppi D, Dinucci D, Errico C, Bártolo P, Chiellini F, 2011, Dual-Scale Polymeric Constructs as Scaffolds for Tissue Engineering, Materials, 4(3): 527542

Norotte C, Marga FS, Niklason LE, Forgacs G, 2009, Scaffold-free vascular tissue engineering using bioprinting, Biomaterials, 30(30): 5910-5917

Osteopore International: www.osteopore.com.sg/

Othon CM, Wu XJ, Anders JJ, Ringeisen BR, 2008, Single-cell printing to form threedimensional lines of olfactory ensheathing cells, Biomed Mater, 3(3): 034101

Ovsianikov A, Schlie S, Ngezahayo A, Haverich A, Chichkov BN, 2007, Two-photon polymerization technique for microfabrication of CAD-designed 3D scaffolds from commercially available photosensitive materials, J Tissue Eng Regen Med, 1(6): 443-449

Pirlo RK, Wu P, Liu J, Ringeisen B, 2012, PLGA/hydrogel biopapers as a stackable substrate for printing HUVEC networks via BioLPTM, Biotechnol Bioeng, 109(1): 262-273

Place ES, George JH, Williams CK, Stevens MM, 2009, Synthetic polymer scaffolds for tissue engineering, Chem Soc Rev, 38(4): 1139-1151

Puppi D, Chiellini F, Piras AM, Chiellini E, 2010a, Polymeric materials for bone and cartilage repair, Prog Polym Sci, 35(4): 403-440

Puppi D, Piras AM, Detta N, Dinucci D, Chiellini F, 2010b, Poly(lactic-co-glycolic acid) electrospun fibrous meshes for the controlled release of retinoic acid, Acta Biomater, 6(4): 1258-1268

Ragaert K, Cardon L, Dekeyser A, Degrieck J, 2010, Machine design and processing considerations for the 3D plotting of thermoplastic scaffolds, Biofabrication, 2(1): 014107

Rai B, Lin JL, Lim ZXH, Guldberg RE, Hutmacher DW, Cool SM, 2010, Differences between in vitro viability and differentiation and in vivo bone-forming efficacy of human mesenchymal stem cells cultured on PCL-TCP scaffolds, Biomaterials, 31(31): 7960-7970

Ringeisen BR, Kim H, Barron JA, Krizman DB, Chrisey DB, Jackman S, Auyeung RY, Spargo BJ, 2004, Laser printing of pluripotent embryonal carcinoma cells, Tissue Eng, 10(3-4): 483-491

Ringeisen BR, Othon CM, Barron JA, Young D, Spargo BJ, 2006, Jet-based methods to print living cells, Biotechnol J, 1(9): 930-948

Rohner D, Hutmacher DW, Cheng TK, Oberholzer M, Hammer B, 2003, In vivo efficacy of bone-marrow-coated polycaprolactone scaffolds for the reconstruction of orbital defects in the pig, J Biomed Mater Res B Appl Biomater, 66B(2): 574-580

Russias J, Saiz E, Deville S, Gryn K, Liu G, Nalla RK, Tomsia AP, 2007, Fabrication and in vitro characterization of three-dimensional organic/inorganic scaffolds by robocasting, J Biomed Mater Res A, 83(2): 434-445 
Sachs E, Cima M, Cornie J, 1990, Three-dimensional printing: Rapid tooling and prototypes directly from a CAD model, CIRP Ann Manuf Technol, 39(1): 201204

Sachs EM, Haggerty JS, Cima MJ, Williams PA, 1993, Three-dimensional printing techniques, US Patent No. 5204055A.

Saunders RE, Gough JE, Derby B, 2008, Delivery of human fibroblast cells by piezoelectric drop-on-demand inkjet printing, Biomaterials, 29(2): 193-203

Schantz JT, Lim TC, Ning C, Teoh SH, Tan KC, Wang SC, Hutmacher DW, 2006, Cranioplasty after trephination using a novel biodegradable burr hole cover: technical case report, Neurosurgery, 58(1 Suppl): ONS-E176; discussion ONSE176

Seitz H, Rieder W, Irsen S, Leukers B, Tille C, 2005, Three-dimensional printing of porous ceramic scaffolds for bone tissue engineering, J Biomed Mater Res B Appl Biomater, 74(2): 782-788

Shanjani Y, De Croos JN, Pilliar RM, Kandel RA, Toyserkani E, 2010, Solid freeform fabrication and characterization of porous calcium polyphosphate structures for tissue engineering purposes, J Biomed Mater Res B Appl Biomater, 93(2): 510519

Shor L, Guceri S, Chang R, Gordon J, Kang Q, Hartsock L, An Y, Sun W, 2009, Precision extruding deposition (PED) fabrication of polycaprolactone (PCL) scaffolds for bone tissue engineering, Biofabrication, 1(1): 015003

Shuai C, Gao C, Nie Y, Hu H, Zhou Y, Peng S, 2011, Structure and properties of nanohydroxypatite scaffolds for bone tissue engineering with a selective laser sintering system, Nanotechnology, 22(28): 285703

Silva NA, Salgado AJ, Sousa RA, Oliveira JT, Pedro AJ, Leite-Almeida H, Cerqueira R, Almeida A, Mastronardi F, Mano JF et al, 2010, Development and characterization of a novel hybrid tissue engineering-based scaffold for spinal cord injury repair, Tissue engineering Part A, 16(1): 45-54

Silva NA, Sousa RA, Pires AO, Sousa N, Salgado AJ, Reis RL, 2011, Interactions between Schwann and olfactory ensheathing cells with a starch/polycaprolactone scaffold aimed at spinal cord injury repair, J Biomed Mater Res A: 470-476

Skardal A, Zhang J, Prestwich GD, 2010, Bioprinting vessel-like constructs using hyaluronan hydrogels crosslinked with tetrahedral polyethylene glycol tetracrylates, Biomaterials, 31(24): 6173-6181

Sobral JM, Caridade SG, Sousa RA, Mano JF, Reis RL, 2011, Three-dimensional plotted scaffolds with controlled pore size gradients: Effect of scaffold geometry on mechanical performance and cell seeding efficiency, Acta Biomater, 7(3): 1009-1018

Stevens MM, George JH, 2005, Exploring and engineering the cell surface interface, Science, 310(5751): 1135-1138

Sun W, Lal P, 2002, Recent development on computer aided tissue engineering -- a review, Comput Methods Programs Biomed, 67(2): 85-103

Tan KH, Chua CK, Leong KF, Cheah CM, Cheang P, Abu Bakar MS, Cha SW, 2003, Scaffold development using selective laser sintering of polyetheretherketonehydroxyapatite biocomposite blends, Biomaterials, 24(18): 3115-3123

Tarafder S, Balla VK, Davies NM, Bandyopadhyay A, Bose S, 2012, Microwavesintered 3D printed tricalcium phosphate scaffolds for bone tissue engineering, $J$ Tissue Eng Regen Med: DOI: 10.1002/term.1555 
Tirella A, Vozzi F, De Maria C, Vozzi G, Sandri T, Sassano D, Cognolato L, Ahluwalia A, 2011a, Substrate stiffness influences high resolution printing of living cells with an ink-jet system, J Biosci Bioeng, 112(1): 79-85

Tirella A, Vozzi F, Vozzi G, Ahluwalia A, 2011b, PAM2 (piston assisted microsyringe): a new rapid prototyping technique for biofabrication of cell incorporated scaffolds, Tissue Eng Part C Methods, 17(2): 229-237

Tsang VL, Bhatia SN, 2004, Three-dimensional tissue fabrication, Adv Drug Deliv Rev, 56(11): 1635-1647

Vozzi G, Flaim C, Ahluwalia A, Bhatia S, 2003, Fabrication of PLGA scaffolds using soft lithography and microsyringe deposition, Biomaterials, 24(14): 2533-2540

Vozzi G, Previti A, De Rossi D, Ahluwalia A, 2002, Microsyringe-Based Deposition of Two-Dimensional and Three-Dimensional Polymer Scaffolds with a WellDefined Geometry for Application to Tissue Engineering, Tissue Eng, 8(6): 1089-1098

Wang F, Shor L, Darling A, Khalil S, Sun W, Güçeri S, Lau A, 2004, Precision extruding deposition and characterization of cellular poly--caprolactone tissue scaffolds, Rapid Prototyping J, 10(1): 42-49

Wang WL, Cheah CM, Fuh JYH, Lu L, 1996, Influence of process parameters on stereolithography part shrinkage, Mater Design, 17(4): 205-213

Wei Ã T, Hildebrand G, Schade R, Liefeith K, 2009, Two-Photon polymerization for microfabrication of three-dimensional scaffolds for tissue engineering application, Eng Life Sci, 9(5): 384-390

Wiggenhauser PS, Müller DF, Melchels FPW, Egaña JT, Storck K, Mayer H, Leuthner P, Skodacek D, Hopfner U, Machens HG et al, 2011, Engineering of vascularized adipose constructs, Cell Tissue Res: 1-11

Will J, Melcher R, Treul C, Travitzky N, Kneser U, Polykandriotis E, Horch R, Greil P, 2008, Porous ceramic bone scaffolds for vascularized bone tissue regeneration, $J$ Mater Sci Mater Med, 19(8): 2781-2790

Williams JM, Adewunmi A, Schek RM, Flanagan CL, Krebsbach PH, Feinberg SE, Hollister SJ, Das S, 2005, Bone tissue engineering using polycaprolactone scaffolds fabricated via selective laser sintering, Biomaterials, 26(23): 48174827

Wiria FE, Leong KF, Chua CK, Liu Y, 2007, Poly-epsilon-caprolactone/hydroxyapatite for tissue engineering scaffold fabrication via selective laser sintering, Acta Biomater, 3(1): 1-12

Woodruff MA, Hutmacher DW, 2010, The return of a forgotten polymerPolycaprolactone in the 21st century, Prog Polym Sci, 35(10): 1217-1256

Wu PK, Ringeisen BR, 2010, Development of human umbilical vein endothelial cell (HUVEC) and human umbilical vein smooth muscle cell (HUVSMC) branch/stem structures on hydrogel layers via biological laser printing (BioLP), Biofabrication, 2(1): 014111

Xiong Z, Yan Y, Wang S, Zhang R, Zhang C, 2002, Fabrication of porous scaffolds for bone tissue engineering via low-temperature deposition, Scr Mater, 46(11): 771776

Xu M, Li Y, Suo H, Yan Y, Liu L, Wang Q, Ge Y, Xu Y, 2010, Fabricating a pearl/PLGA composite scaffold by the low-temperature deposition manufacturing technique for bone tissue engineering, Biofabrication, 2(2): 025002 
Yeong WY, Sudarmadji N, Yu HY, Chua CK, Leong KF, Venkatraman SS, Boey YC, Tan LP, 2010, Porous polycaprolactone scaffold for cardiac tissue engineering fabricated by selective laser sintering, Acta Biomater, 6(6): 2028-2034

Yilgor P, Yilmaz G, Onal MB, Solmaz I, Gundogdu S, Keskil S, Sousa RA, Reis RL, Hasirci N, Hasirci V, 2012, An in vivo study on the effect of scaffold geometry and growth factor release on the healing of bone defects, J Tissue Eng Regen Med: DOI: $10.1002 /$ term.1456

Yoo JJ, Atala A, Binder KW, Zhao W, Dice D, Xu T, 2011, Delivery system, US Patent No. 2011/0172611 A1.

Zhou WY, Wang M, Cheung WL, Ip WY. 2010, Selective Laser Sintering of Poly (LLactide)/Carbonated Hydroxyapatite Nanocomposite Porous Scaffolds for Bone Tissue Engineering in Tissue Engineering, eds. Eberli D, InTech, 179-204.

\section{Captions for Figures}

Figure 1. Schematic representation of some basic steps in scaffold-based TE approach involving a) data acquisition by medical imaging technique, b) and c) 3D computer solid model of tissue defect and biomimetic scaffold, d) and e) layer-by-layer 3D scaffold manufacturing, f) and g) cell seeding and dynamic cell culturing of tissue engineered construct, h) and i) scaffold implantation and tissue regeneration.

Figure 2. Proposed classification of the AM techniques commonly employed in TE.

Figure 3. Schematic representation of the most commonly AM techniques employed in TE. a) Stereolithography (SLA): layers of a photosensitive polymer are selectively polymerized by a laser or an UV light; b) Selective Laser Sintering (SLS): a powder bed is selectively sintered using a high intensity laser beam; after the generation of a layer, a new powder bed is spread mechanically by a roller; c) Three-Dimensional Printing (3DP): using an ink-jet head, a binder material is selectively laid on a powder layer, then a new layer of powder is placed on top of the previous one and the process of deposition restarts; d) Fused Deposition Modeling (FDM): a polymeric filament is extruded through a heated nozzle, and the polymer melt is continuously deposited on a construction platform to build the scaffold layer-by-layer. 
a) Data acquisition

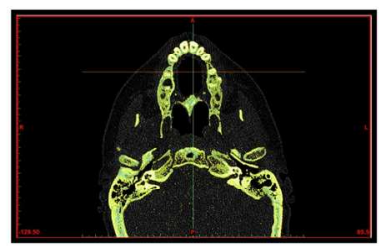

b) 3D CAD of the original defect anatomy
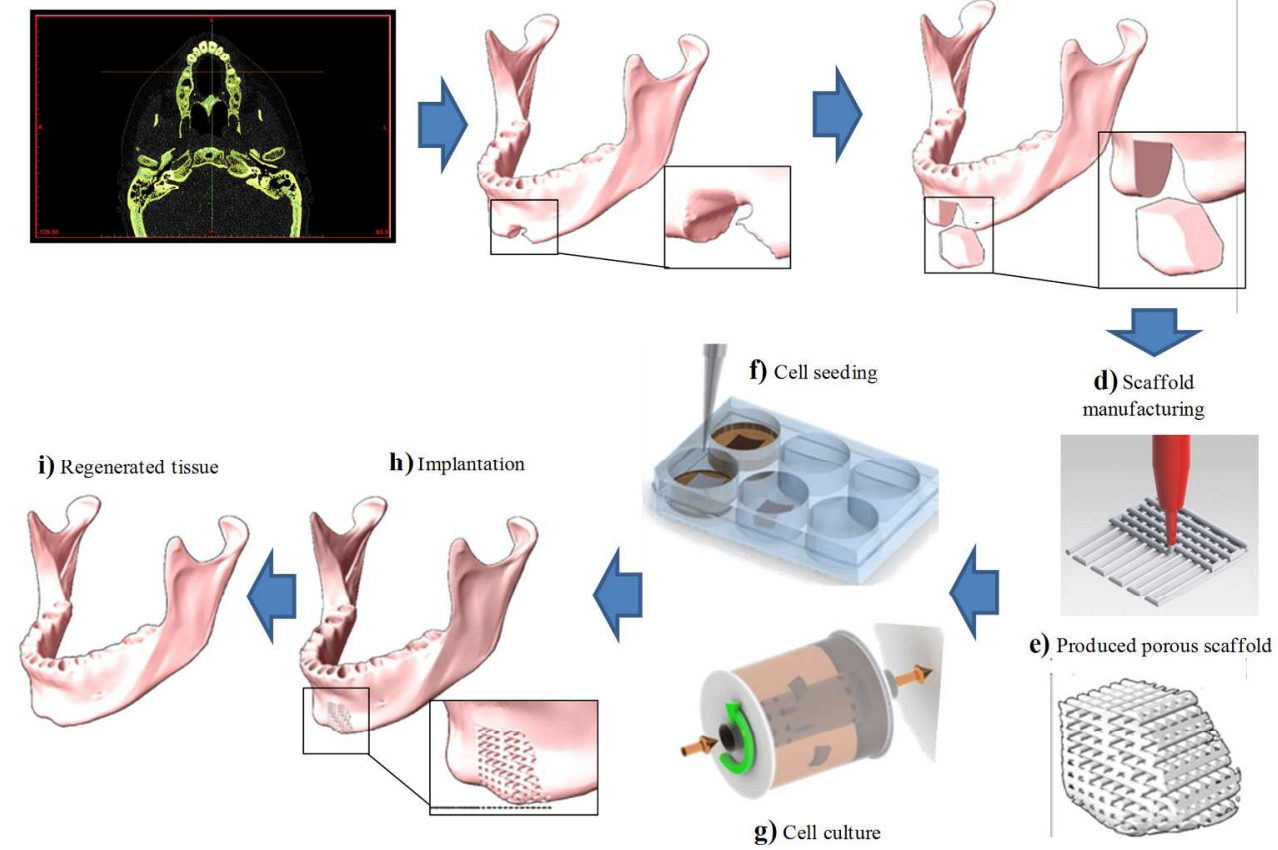

$176 \times 127 \mathrm{~mm}(300 \times 300$ DPI $)$ c) $3 \mathrm{D} \mathrm{CAD} \mathrm{of} \mathrm{the} \mathrm{final} \mathrm{defect} \mathrm{anatomy}$ and of the biomimetic scaffold

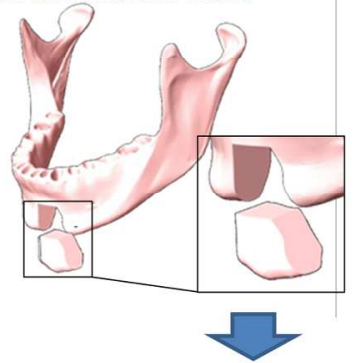

d) Scaffold manufacturing 


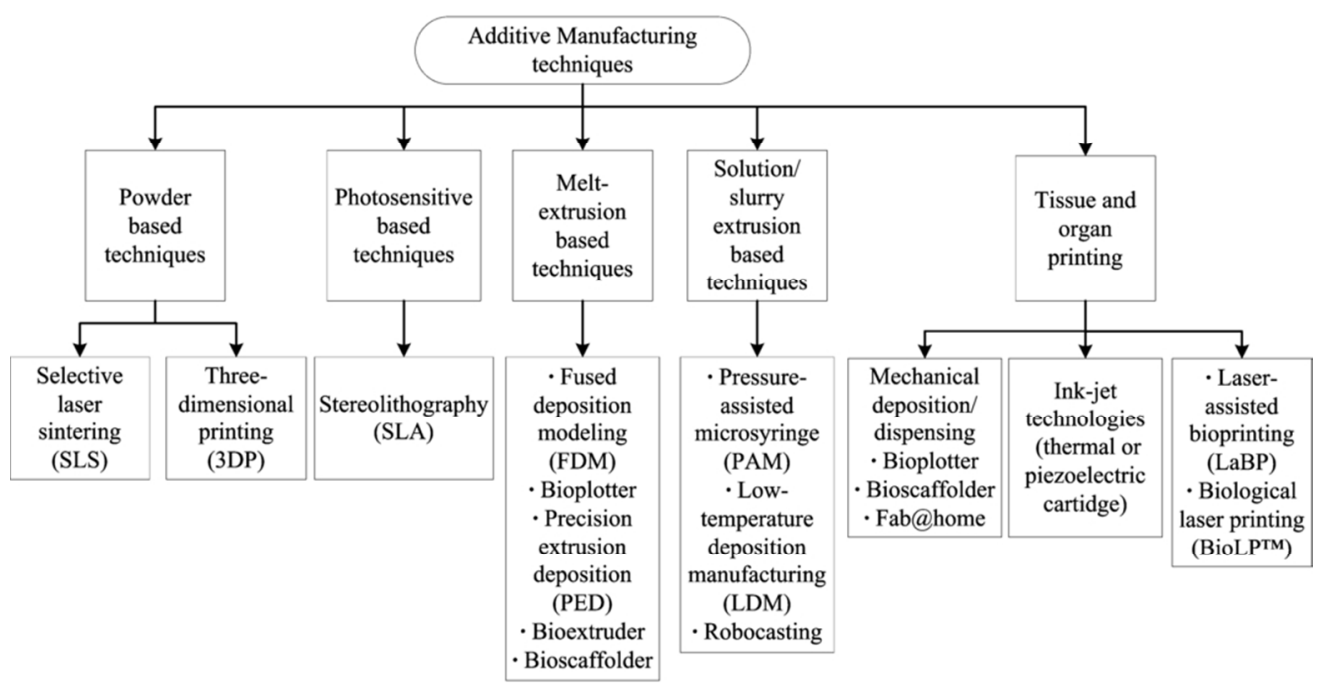

$89 \times 47 \mathrm{~mm}(300 \times 300 \mathrm{DPI})$ 
a) Stereolithography (SLA)

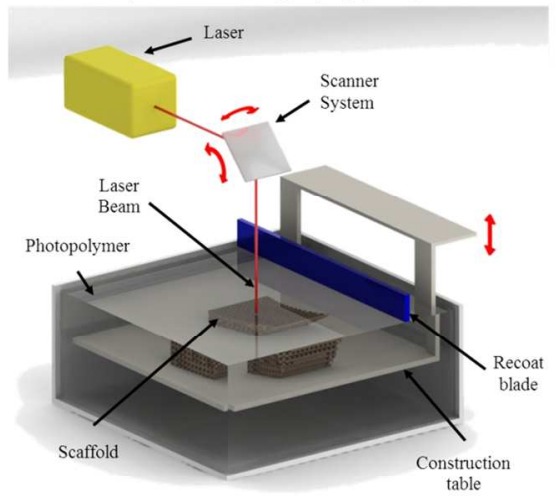

c) Three Dimensional Printing (3DP)

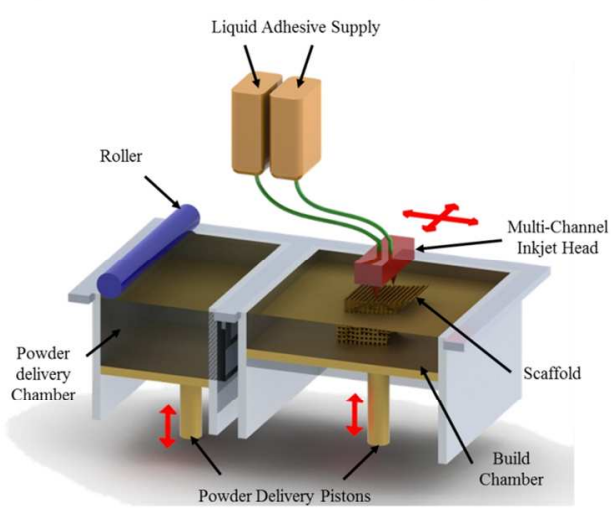

b) Selective Laser Sintering (SLS)

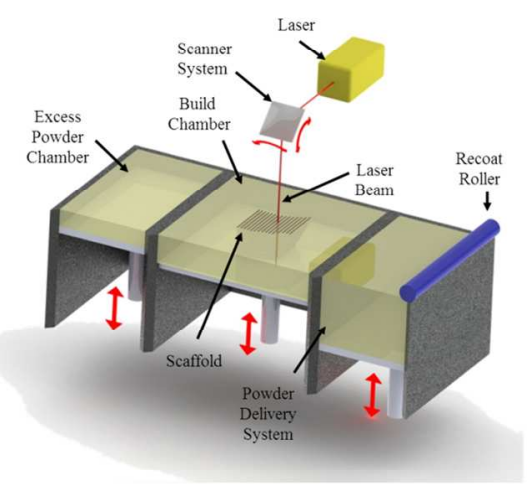

d) Fused Deposition Modelling (FDM)

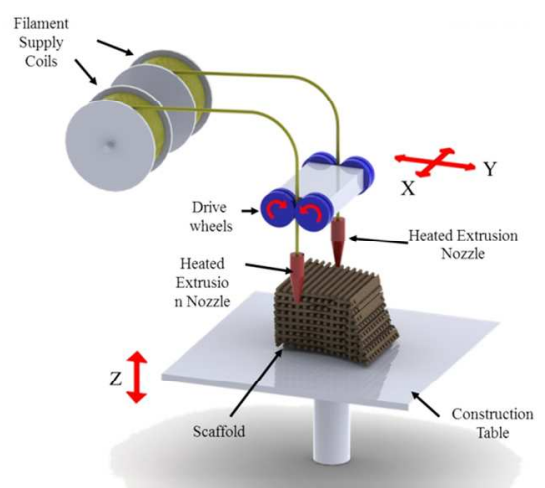

$169 \times 164 \mathrm{~mm}(300 \times 300 \mathrm{DPI})$ 